\title{
A REPETIÇÃO COMO ELEMENTO CONDUTOR DO TÓPICO DISCURSIVO
}

Maria Lúcia da Cunha Victório de Oliveira Andrade *

RESUMO: Neste trabalho, busca-se observar como, após uma digressão, o uso de repetições torna-se um elemento condutor do tópico discursivo prévio. A digressão caracteriza-se por ser um tipo de movimento que suspende momentaneamente o tópico discursivo em andamento, trazendo uma cadência própria ao desenvolvimento textual. Para o estudo das repetições, seguiu-se a proposta de Marcuschi (1992), cuja tipologia está dividida em dois níveis: formal e funcional.

Palavras-chave: digressão, repetição, tópico discursivo.

\section{INTRODUÇÃO}

propósito deste trabalho é observar como, após uma

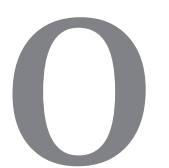
digressão, o uso de repetições torna-se um elemento condutor do tópico discursivo prévio. A digressão caracteriza-se por ser um tipo de movimento que suspende momentaneamente o tópico discursivo em andamento, trazendo uma cadência própria ao desenvolvimento textual. Não se trata apenas da suspensão de um tópico, mas principalmente da produção de um novo tópico sem relação imediata com o discurso em andamento ou que o precedeu ou o sucedeu.

Tem-se, portanto, um tipo de interrupção das atividades comunicativas em que o domínio de relevâncias tópicas associado ao tema em andamento apresenta baixa relevância imediata, tornandose marginal. Como lembram Dascal e Katriel (1979, p. 78), "uma digressão pode ser caracterizada por duas mudanças tópicas sucessivas

Universidade de São Paulo. 
envolvendo os mesmos dois tópicos”. Esquematizando essa explicação, tem-se:

1a. etapa: retirada de um tópico (A);

2a. etapa: introdução de um tópico (B);

3a. etapa: retirada do tópico (B);

4a. etapa: reintrodução do tópico (A).

A digressão se localiza na 2a. e 3a. etapas.

Ao analisar a digressão, é preciso esclarecer o que se entende por tópico discursivo. Em linhas gerais, o tópico pode ser definido como "aquilo sobre o que se está falando" (Brown e Yule, 1983, p.73), ou seja, aquilo que os interlocutores tomam como "assunto" ou "tema" da conversa. Com base nessa conceituação, pode-se dizer que o tópico é um elemento essencial não só para definir os processos de colaboração e envolvimento entre os interlocutores na determinação de núcleos comuns, como também para revelar a forma dinâmica pela qual a conversação se estrutura.

Veja-se o exemplo a seguir:

(1) No D2 360 (NURC/SP), L2 está desenvolvendo o tópico "Cotação de algumas profissões", mas o interrompe para explicar como funcionam as agências de emprego. Após a interrupção, L2 volta a desenvolver o tópico prévio e este é reintroduzido pelo marcador então ("então eu estava explicando...") e a repetição ${ }^{1}$ do trecho anterior ao tópico digressivo ("para cada cem engenheiros"), assinalando a retomada do fluxo temático:

L2 ) por isso eu vejo pelo meu marido... como eu falei para vocês ele faz seleção de pessoal né?... então... ele diz que para... por exemplo cada cem engenheiros que é pedido... ele funciona do seguinte modo as firmas precisam... de um em/ de um cara então ah

${ }^{1}$ As repetições são marcadas por grifo. 
Filologia e Lingüística Portuguesa, n. 2, p. 179-204, 1998.

por exemplo (ah) um:: ( ) um banco precisa de um diretor de um banco chega para ele diz assim "eu preciso de um diretor de banco para tal tal área para fazer isso assim assim assim" ... então ele vai procurar... certo?... ou então chega uma outra firma e diz assim "preciso... um:: um gerente de::.... de produção:: o gerente de ( )" normalmente é um engenheiro isso isso isso então eu estava explicando... que para cada cem engenheiros que são pedidos... é pedido UM advogado... quer dizer a desproporção é inCRÍvel...

(SP D2 360: 898-911, p. 158-9)

Como se pode verificar através do exemplo dado, a escolha de um desenvolvimento tópico marginalmente relevante, em geral, vem manifestada por algum tipo de marca que se segue ao trecho digressivo: uso de repetições (de constituintes ou de orações) ou de um marcador conversacional. Esse tipo de marca funciona, conforme observa Marcuschi (1990, p.1), "como estratégias de monitoração rítmica de coerência, favorecendo a coesão superficial e auxiliando a geração de sequências mais compreensíveis. Propiciam uma textualidade sobretudo no caso das repetições mútuas. Tornam-se, assim, um mecanismo que contribui para a sintaxe e organização discursiva".

Na verdade, essas repetições caracterizam um planejamento administrado passo a passo. Na produção oral os padrões sintáticos estão intimamente relacionados aos padrões interacionais, de modo que determinadas propriedades sintáticas de superfície são controladas, no nível discursivo, em função de necessidades comunicativas. Entretanto, as atividades interacionais são geradas no fluxo de padrões sintáticos em andamento que operam com base sobretudo para a topicalidade e a argumentação. Assim, digressão e repetição não podem ser estudadas como meros descontinuadores textuais, mas como elementos que fazem parte de uma atividade de composição textual, visando à condução do tópico discursivo. 
ANDRADE, Maria Lúcia da C. V. de Oliveira. A repetição como elemento condutor do tópico discursivo.

\section{DIGRESSÃO $\in$ CONTINUIDADE TÓPICA}

A continuidade tópica pode ser observada pela exterioridade dos segmentos. A um segmento textual pode seguir-se um outro que volta ao anterior, ou um outro segmento que é externo ao anterior. Esse segmento pode ser marcado por um nexo de coordenação (e, mas agora, então, etc.) inicial e, deste modo, seu caráter fica evidenciado, ou pode ser estabelecido implicitamente.

Por outro lado, a progressão do texto também é feita por retomadas, e é assim que, através de repetições, vão ocorrendo os pinçamentos que recuperam elementos enunciados antes de uma digressão e necessários ao próprio avanço do texto. A repetição é, portanto, básica para o estabelecimento da continuidade tópica.

A categoria da continuidade decorre, segundo Koch et alii (1992, p. 364), "de uma organização sequiencial dos segmentos tópicos, de forma que a abertura de um apenas se dá após o fechamento do outro, precedente". Essa organização sequencial pode ser evidenciada por marcas linguísticas (repetições, marcadores conversacionais, etc.) que possuem também reconhecido valor discursivo e/ou pragmático.

\section{OCORRÊNCIA DE REPETIÇÕES}

A repetição (R) é, conforme observa Marcuschi (1990, p.1), "a produção de segmentos discursivos idênticos ou semelhantes duas ou mais vezes no âmbito de um mesmo evento comunicativo". O autor acrescenta que a matriz (M) -termo que designa a primeira entrada de um segmento discursivo que depois será repetido - caracteriza-se por operar como base ou modelo para a projeção de outro segmento construído à sua identidade ou semelhança, ou seja, a repetição. Nessa perspectiva, a matriz pode condicionar a repetição nos níveis: fonológico, morfológico, sintático, lexical, semântico ou pragmático. Entretanto, cabe ressaltar que a criatividade ou a atividade reformuladora 
podem ser verificadas, visto que a repetição não é um "espelhamento automático" e a matriz funciona de forma paradigmática em sua relação com o segmento repetido.

Considerando que é sempre produzida visando a uma finalidade, a repetição apresentará traços de seletividade em relação à sua matriz. Essa relação se dá na seleção e marcação de um foco localizado em algum ponto da cadeia de constituintes em relação à matriz. Desse modo, a matriz opera como proposta de composição textualdiscursiva, ou seja, é a base para a topicalidade e a argumentação. Por meio da repetição do segmento matriz, o falante faz uso de um mecanismo de composição textual, visando a assegurar a condução do tópico discursivo em andamento e também a compreensão.

As digressões são, como já se viu anteriormente, porções textuais inseridas no tópico discursivo em curso, visto que elas propiciam um parêntese ou interrupção da atividade comunicativa em que o conjunto das relevâncias tópicas associadas ao tema em andamento tem baixa relevância imediata, ou seja, é marginal.

A volta ao tópico prévio se dá a partir de marcas formais como repetições de constituintes ou repetições oracionais, isto é, segmentos que já haviam sido mencionados e que agora reintroduzem o tópico. Segundo Gardner (1987, p. 134), as ligações entre os tópicos são marcantes e podem apresentar um caráter referenciador "retrospectivo e prospectivo".

Para um estudo das repetições, seguiu-se a proposta de Marcuschi (1992), cuja tipologia está dividida em dois níveis: formal e funcional.

\subsection{Tipos formais}

Em sua dimensão formal, as marcas relativas à repetição empregada após a ocorrência de digressão apresentam, seguindo a proposta de Marcuschi (1992, p. 49-58), aspectos relativos a: 
ANDRADE, Maria Lúcia da C. V. de Oliveira. A repetição como elemento condutor do tópico discursivo.

a- produção

Considerando-se a relação entre os participantes (estrutura de participação), tem-se dois tipos de R: auto-repetição (em que a M e a R são produzidas pelo mesmo falante e heterorrepetição (em que a $M$ e a $\mathrm{R}$ são efetuadas por falantes distintos).

Vejam-se, a seguir, exemplos de auto-repetição:

(2) L1 e quando as gêmeas nasceram... eu me afastei do serviço...

L2 ( )ahn ahn

L1 eu trabalhava no serviço social do Estado...

L2 uhn

L1 fazendo parte da:: campanha de:: repressão à mendicância... do governo Carvalho Pinto

L2 ahn ahn

L1 mas:.... trabalhava al/nos::albergue noturno...

L2 ahn

L1 eh como assistente social sabe? embora não:...

L2 sei

L1 não tivesse curso

L2 uhn

L1 mas::... eu fazia o atendimento do pessoal.. encaminha::va... e::... depois então eu tive que deixar... fui obrigada a deixar dada a dificuldades...

(SP D2 360: 423-39, p. 147)

Nesse segmento, L2 introduz o tópico "O abandono da vida profissional de L1 por causa dos filhos", fazendo uma pergunta a L1. Esta começa a desenvolver o tópico respondendo que chegou a trabalhar só no início de casada e quando as filhas gêmeas nasceram, ela se 
Filologia e Lingüística Portuguesa, n. 2, p. 179-204, 1998.

afastou. A seguir, L1 faz uma digressão lógico-experiencial ${ }^{2}$, introduzindo o tópico "Natureza da atividade profissional de L1". A digressão é percebida não só pela mudança de relevância tópica (abandono da vida profissional) para relevância marginal (tipo de atividade profissional), mas também pela mudança discursiva temporal: de "me afastei" (pretérito perfeito narrativo) para "eu trabalhava" (pretérito imperfeito narrativo-descritivo). L1 denuncia o esgotamento da digressão fazendo alongamentos e pausas de hesitação $\left(2,5^{\prime \prime}\right)$ e, finalmente, reintroduzindo o tópico por meio da repetição "eu tive que deixar", antecedida do marcador "depois então".

(3) L1 porque... eu fiz o curso normal... porque eu havia perdido o meu pai fazia:: ah no no primeiro colegial. e:: eu precisava ter uma ah optar por uma carreira pro/- meu relógio está atrapalhando a nossa -... por uma carreira profissionalizante... eu achei que as coisas dali para frente seriam mais difíceis eu comecei o colegial....

(SP D2 360: 1562-7, p. 175)

$\mathrm{L} 1$ responde a uma pergunta de $\mathrm{L} 2$, introduzindo o tópico "Necessidade de carreira profissionalizante de L1". Nesse segmento, a locutora diz por que escolheu a carreira profissionalizante, mas interrompe o desenvolvimento do tópico e faz uma digressão interpessoal imediata ao mencionar o problema do horário: "meu relógio está atrapalhando a nossa-...”. A interrupção é rápida e relaciona-se a algo que está presente no entorno e torna-se relevante para o locutor. Ao introduzir o tópico prévio, verifica-se que L1 repete a última estrutura utilizada antes da digressão: "por uma carreira profissionalizante..."

(4) Doc existe por exemplo:: proveito digamos monetário para ela ou não? 
L2 que que você vê esse pessoal de teatro... para mim é::é a classe mais sofrida que tem... entende? para mim ele esses daí... se dedicam entende? EU acho esse é o meu ponto de vista eles... investimento deles... é como você jogar na Bolsa talvez pior até entende?... o:: rapaz aí o Altair Lima que montou Hair ele levantou uma nota... ele... agora você pergunta assim o artista ou você perguntaria o produtor?

Doc não mas... em geral tudo... então se você quisesse falar se você faz hum distinção você pode falar dos dois (no caso)...

L2 você vê o:: o:: o Altair Lima ele é... arriscou está certo... ele arriscou ele pôs tudo:: segundo declaração dele não sei se são demagógicas ou não ele pôs... tudo que ele tinha na na montagem da peça Hair...

(SP D2 62: 1277-93, p. 91)

O documentador pergunta aos intelocutores se eles acreditam que haja algum tipo de proveito monetário para a pessoa que desempenha alguma atividade para a qual não se encontra uma especialização. Tal pergunta foi imediatamente respondida por L2, mas no decorrer de sua exposição o falante faz uma pausa e, após usar o marcador agora, solicita um esclarecimento, já que se referiu ao pessoal de teatro de forma genérica. Esse pedido é feito através de uma digressão retórica didática, visto que é uma resposta a um enunciado anterior não totalmente aceito ou compreendido. $\mathrm{O}$ que a distingue do material conversacional em que está encaixada é o fato de desempenhar uma função metalinguística ou metaconversacional. Pode-se dizer, então, que ela marca uma espécie de salto e é notada como uma pausa no fluxo informacional. Depois de sanada a dúvida, L2 retoma o tópico, fazendo uso da repetição do referente "Altair Lima".

Quanto às heterorrepetições, destacam-se os seguintes exemplos: 
(5) L1 eu fui ver um filme Ó::timo... Vestígios do Dia...

L2 ah:: me falaram que É muito bom

L3 neste fim de semana?... você viu Filadéfia?

L1 vi sim... vi semana passada... este::fim de sema::na vi...

L3 é BOM?

L1 eu NÃO gostei muito... achei MUIto TRISte porQUE é um filme sobre AIds e preconceito né?... o raPAZ ele é mandado embora é um advogado ilustre...ele não É mandado embora porque tinha aids É mandado embora porque é homossexual... porque uma coLEga que tem aids e que NÃO É mandada embora... quer dizer enTÃO fica CLAro que a firma usou dois pesos duas medidas

L2 aí ele entra na justiça

L1 ENTÃO:: ele entra na justiça... o filme é isso... e Filadélfia é a cidade dos direitos humanos...o FILme é MUI::TO bem interpretado MAS é um filme cheio de clichês POR exemplo é um filme que deseja mostrar que os Estados Unidos são no fim das contas O:: PAÍS da justiça... onde MESmo que seja intoleRANte... você con::trata um BOM advogado o advogado GAnha a CAUsa pra você É um filme ameriCAno deMAIS:.... pro meu gosto... Ele só vale pela interpretação de Tom Hanks que traBAlha muito bem MAS a história É simples... MAS bom mesmo é Vestígios do Dia... esse filme é impressionante

L2 você assistiu Vestígios do Dia?

L3 ainda não tive tem::po

L1 é LIN::do é:: impressioNANTE... é uma adaptação né? (Conversação Espontânea 1) 
L1 introduz o tópico "Último filme visto no cinema", comentando a respeito de "Vestígios do dia", mas é interrompido por L3 e todos os interlocutores começam a falar sobre outro filme, "Filadélfia". Após uma longa digressão lógico-experiencial sobre este último filme, L1 volta a introduzir o tópico relacionado a "Vestígios do dia".

No exemplo, a digressão baseia-se numa relação paradigmática ou associativa evocada a partir do intem lexical filme, produzido por L1 em "eu fui ver um filme ó::timo... Vestígios do Dia...”. Vocábulo este que leva L3 a fazer uma associação com outro filme, deslocando o tópico sobre "Último filme visto" agora para "Filadélfia". A volta ao tópico é feita por $\mathrm{L} 1$ que, depois de responder ao amigo, retoma a expressão avaliativa usada para caracterizar o filme, mas com variação: "bom mesmo é".

(6) L1 ... mas o Rocha:: e o:: e o::... e o:: Clark tinha um tipo especial de calçado...

L2 Casa Clark exatamente

L1 então esse calçado tinha um:: formato mais ou menos do pé... bico redondo... e levantado na ponta... para aconchê/para dar liberdade aos dedos... chamava-se commonwealth se não me engano esse calçado...

Doc como é que chama?

L1 commonwealth...

Doc ahn

L1 eu não falo não pronuncio direitinho... escrevia-se comonvealt não é?... não pro/não tenho boa pronúncia hoje não tenho... nunca tive boa pronúncia no inglês... no inglês eu fui sempre muito ( )... em inglês... mas...

L2 éh:: apesar de mamãe ( )... 
Filologia e Lingüística Portuguesa, n. 2, p. 179-204, 1998.

L1 sapatos... muito cômodos muito confortáveis muito cômodos...

(SP D2 396: 964-77, p. 204)

L1 está explicando como era o formato do sapato feito pelo Clark e utiliza um termo em inglês, entretanto a documentadora não compreende e pede um esclarecimento, instaurando uma digressão retórica didática. Esse pedido é feito, empregando-se a repetição do verbo chamar.

(7) L1 RICARdo... eu preciso fazer uma::as gravações de pequenos diálogos... mais ou menos dez minutos para poder usar com meus alunos em sala de aula...voCÊ não quer fazer pra mim?...

L2 como assi::m? você precisa de gravações de fala espontânea?

L1 se puder ser espontânea é melhor...

L2 tá bem... vou ver se consigo...

L1 ÓTIMO... mas você também pode gravar pequenas interações entre você e um vendedor por exemplo... quer dizer uma transação comercial... o que eu preciso MESMO é que os diálogos sejam curtos para que os alunos percebam como se dá a interação

(Conversação Espontânea 3)

L1 introduz o diálogo a partir do tópico "Necessidade de fazer gravações" e solicita a ajuda de L2. Entretanto, L2 pede um esclarecimento em relação ao tipo de gravação desejada. Para esse pedido, L2 repete parte da fala de seu interlocutor: "você precisa de gravações espontâneas?”. Tem-se aqui uma digressão retórica didática, já que a linguagem é usada em sua função metalinguiística, evidenciando o modo 
do discurso. Após uma avaliação da resposta dada por L2 (“ÓTIMO...”), L1 volta a falar no tipo de gravações de que necessita para usar com seus alunos ("mas você pode gravar pequenas interações...").

Quanto à estrutura da troca , a R pode ser instaurada no mesmo turno (intraturno, exemplos 1 e 3 ) ou em turnos diferentes (interturno, exemplos 5 e 6 ).

\section{b- segmento}

Embora não haja um método consensual para se considerar a divisão dos segmentos repetidos, sua marca diz respeito a unidades de estrutura da língua. As marcas segmentais aqui consideradas são: lexema (exemplos 4 e 6), sintagma (exemplo 3) e oração (exemplos 1 e 7).

\section{c- distribuição}

De acordo com sua colocação no texto, as R usadas para voltar ao tópico prévio apresentam as seguintes posições: proximidade (exemplos 8,9 - colocados a seguir) e distanciamento (exemplos 1 e 3 ). Para essa divisão, foram adotados os pressupostos estabelecidos por Marcuschi (1992) em relação aos princípios organizacionais do texto que postulam a linearidade linguiística e a sequienciação hierárquica da estrutura informacional, relativa à organização tópica e ideacional do texto.

A R-próxima distingue-se da R-distanciada pelo fato de a primeira ocorrer no espaço interno de um tópico discursivo, enquanto a segunda instaura-se na retomada de um tópico discursivo.

Cabe apontar que as R-próximas encontradas no corpus restringem-se às R que estabelecem uma digressão retórica didática ou persuasiva, já que revelam um pedido de esclarecimento em relação a um enunciado anterior não totalmente aceito ou compreendido. Na verdade, não se tem um novo tópico, mas uma mudança em relação ao foco. Passa-se de um ponto de centração a outro, isto é, há um deslo- 
camento da relevância tópica para uma relevância de ordem metaconversacional ou metalinguiística. seguir:

Para melhor compreensão desse tipo de R, veja-se o exemplo a

(8) L1 você acha que... desenvolvimento é BOM ou ruim?

L2 desenvolvimento em que sentido?

L1 crescimento... o Brasil diz-se basicamente subdesenvolvido e diz-se também que ele está crescendo... se desenvolvendo... parece que está saindo de uma... condição de subdesenvolvido para chegar sei lá numa de desenvolvido... okay?...uma :: um caminho

L2 ahn ahn

L1 agora PE::gue... os indivíduos... desse país... é melhor ou é pior para eles isso?

L2 não sei porque acho que aí quando se fala em desenvolvimento geralmente está se falando num plano material né? ((...))

(SP D2 360: 497-509, p. 29-30)

L2 pede uma informação sobre o sentido do termo desenvolvimento (ato de fala clarificatório), pois é provável que não o tenha compreendido totalmente, evidenciando que o contexto de conhecimento de mundo não é plenamente partilhado pelos dois participantes. Para poder sanar a dúvida da interlocutora e garantir a inteligibilidade do discurso, $\mathrm{L} 1$ relaciona o termo que causou toda a dificuldade a outro (crescimento); a seguir, para deixar mais evidente ainda o significado pretendido, faz uso de um exemplo ("agora PE::gue... os indivíduos... desse país... é melhor ou pior para eles isso?”).

Neste caso a R-próxima se estabelece entre a pergunta feita por $\mathrm{L} 1$ e o pedido de esclarecimento de $\mathrm{L} 2$. A resposta de L1 se faz através de construções parafrásticas com o intuito de expandir a noção de 
desenvolvimento: ação ou ato de sair da condição de subdesenvolvimento. Após a digressão retórica didática, L2 tem condições de responder à questão proposta e faz uso da repetição do termo desenvolvimento para voltar ao tópico prévio.

Cabe aqui um breve esclarecimento sobre a distribuição das R. Marcuschi considera uma R-próxima aquela que ocorre logo após uma interrupção com um desvio ou digressão e uma retomada imediata do tópico que vinha sendo desenvolvido. $O$ autor acrescenta ainda que essas interrupções são inserções breves e apresentam caráter explicativo. Talvez um exemplo desse caso pudesse ser o trecho a seguir:

(9) L1 ... uma assistência... adequada... que se impõe... principalmente em casos em que o associado não tem realmente... condições... porque:: não dispõe de uma bagagem de conhecimento jurídico... que possa realmente levar à frente ... ou levar adiante... a sua questão... para isso o sindicato dispõe de um departamento jurídico... como o caso por exemplo é o caso do sindicato dos comerciários... departamento jurídico esse que está realmente à altura de prestar toda e qualquer assistência a seus associados principalmente naquelas questões...

(RE DID 131: 92-102, p. 3)

Nesse segmento, o locutor está desenvolvendo o tópico relativo a "Assistência jurídica prestada pelo sindicato", faz uma breve interrupção para introduzir uma inserção de caráter explicativo. Entretanto, casos como esse não podem ser tratados como digressão, pois não se chega a focalizar um outro ponto de relevância.

Quanto às R-distanciadas, são aquelas empregadas logo após o estabelecimento de digressões lógico-experienciais ou interpessoais, 
com a finalidade de retomar o tópico prévio, como se pode observar no exemplo a seguir:

(10) L1 mudou completamente o clima de São Paulo... e os hábitos também mudaram porque houve então... o que aconteceu... houve a::... a inVASÃO:: de São Paulo... (por)... por por pessoas::... não só de fora... principalmente de fora... cresceu muito depois da guerra... imigração... e::... e do Norte sobretudo do Norte... então aí mudou mudaram-se os hábitos mudou... aquela::... eu por exemplo quando ia à cidade... mo::ço e mesmo depois de casado mesmo depois de ter filho da - aliás meu filho até esta/... sempre deu/... ch/ eh ch/ch/ me chamava atenção nisso... mesmo quando eu vinha do interior depois e ter morado no interior eu atravessava a cidade... "T. como vai?... como cai O. como vai?"... no centro da cidade a gente encontrava ce/cenTEnas de::... Todo mundo se conhecia...

L1 ahn

L2 até mil nó/ até mil novecentos e quarenta todo mundo se conhecia em São Paulo...

Doc ( ) éh::?

L1 (tod/é verd/ rodava pela) cidade éh::... rapazes todos se conheciam... depois de quarenta não agora ( ) a gente vai para a cidade não conhece mais ninguém:: em absoluto... porque::: foi TANta gente vindo de fora tanto... tantos advenas...

L2 estran::estrangeiros não é?

L1 que já não se:: né?... então mudaram se os hábitos... mudaram-se completamente aqué/as famílias já não...não têm mais a grande intimidade já não se 
ANDRADE, Maria Lúcia da C. V. de Oliveira. A repetição como elemento condutor do tópico discursivo.

conhecem nem os rapazes quanto mais as famílias... isso depois de quarenta...

(SP D2 396: 619-49, p.195-196)

L1 está desenvolvendo o tópico "Clima da época", falando a respeito da mudança de clima. A seguir, passa a comentar sobre alteração nos hábitos das pessoas. Para exemplificar essa mudança, passa a relatar como as pessoas tinham certa intimidade e como ele era tratado ao encontrar amigos ou conhecidos no centro da cidade, criando uma digressão lógico-experiencial. A volta ao tópico se dá por meio de repetição da expressão "mudaram-se os hábitos", introduzida pelo marcador então.

\section{d- configuração}

Este aspecto refere-se à relação estabelecida entre uma $\mathrm{R}$ e sua $M$. Tal relação pode ser de literalidade (R idêntica, como se verifica nos exemplos 4 e 10) ou de variação. Esta última pode ser equivalente quanto à forma, ou seja, há equivalência de ordem lexical ou estrutural (exemplos: 1, 3, 6 e 7). Entretanto, também pode ocorrer uma variação relativa ao conteúdo, isto é, entre a $\mathrm{R}$ e a $\mathrm{M}$ há equivalência ou similaridade de natureza semântica (exemplos 2: eu me afastei/eu tive que deixar; e 10: ele fica duas horas/ ele passa horas).

\subsection{Tipos funcionais}

Quando se busca fazer um levantamento das funções da repetição, é preciso ter em mente, segundo Koch (1994, p.155), que este mecanismo apresenta multiplas funções potenciais e que tais funções não são excludentes, de modo que a classificação a que se chega é feita em termos de predominância relativa de uma das propriedades ou de sua presença em grau mais elevado. 
Marcuschi apresenta uma tipologia de funções baseada em fatores textuais (funções constitutivas do texto) e discursivos (funções de caráter pragmático e interacional). Revela ser bastante complexo estabelecer essa distinção, pois os dois níveis são interligados. Buscando trabalhar os critérios adequadamente, situa as funções textuais na ordem da linearidade do texto e as discursivas no que se vincula à compreensão, às necessidades argumentativas e aos aspectos interacionais.

\subsubsection{Funções Textuais}

Em suas funções textuais, a $R$ pode apresentar marcas de coesão referencial e sequiencial.

\section{a- referencial}

Segundo a teoria da referência (cf. Lyons, 1977), dois elementos se repetem referencialmente quando têm o mesmo referente, seja este um objeto, um indivíduo, um fato ou um conteúdo proposicional. A R com função coesiva referencial opera no sentido de confirmação do referente. No exemplo (7), o trecho inserido tem como objetivo uma expansão ou determinação do referente (Altair Lima: produtor ou artista); a R é usada com a finalidade de confirmar o dito, resgatando o elemento denominado no mesmo ambiente sintático:

"Altair Lima que montou Hair ele levantou uma nota

o::o:: o Altair Lima ele é... arriscou está certo...

$$
\begin{aligned}
& \text { ele arriscou } \\
& \text { ele... pôs tudo::" }
\end{aligned}
$$

b- seqüencial

Diz respeito a uma relação textual em que o aspecto referencial é pressuposto e, portanto, não há necessidade de ser focalizado. A 
sequienciação é estabelecida pela conjetura de preservação dos referentes; pela manutenção do mesmo nível informacional e comunicativo quanto à cadeia tópica; pela produção de conectividade com base em relações lógicas; pela preservação da prosódia como identificadora e delimitadora de unidades.

A coesão sequiencial é uma progressão linear produzida pelos materiais linguiísticos envolvidos na organização e encadeamento informacional. Nesta conformação, a R evidencia-se como uma estratégia eficaz para a sequienciação de unidades, favorecendo uma coesividade forte e instaurando a progressão tópica. Um caso típico deste tipo de R é o que ocorre no exemplo (13),citado anteriormente, pois contribui para a progressão temática, já que opera no nível das relações intra e interfrasais próximas e não em um contexto discursivo mais amplo.

Importa salientar que a progressão temática tem a ver também com o aspecto discursivo; entretanto, é mais adequado analisá-la nos processos de coesão textual em sentido estrito e não na linha do tópico discursivo (cf. Marcuschi, 1992, p. 118), visto que não há mudança de centração, tratando-se, portanto, do mesmo tópico. Nessa perspectiva, pode-se afirmar que, quando as relações entre os segmentos repetidos se tornam mais distanciadas e não formam uma cadeia sequiencial, elas são incluídas sistematicamente no conjunto de repetições com funções discursivas.

\subsubsection{Funções Discursivas}

As funções discursivas estão relacionadas ao papel da $\mathrm{R}$ no que diz respeito à facilitação da compreensão, à condução do tópico discursivo, à argumentação e à interação. Segundo Marcuschi (1992), o ponto crucial da análise de tais funções reside no tipo de condicionamento a que estão submetidas. Condicionamentos que estão liga- 
dos, de modo geral, às atitudes dos falantes, o que envolve um alto grau de subjetividade, podendo gerar problemas para a análise.

Para se chegar a uma definição razoavelmente explícita dessas funções, é preciso observar suas evidências empíricas que se encontram tanto nos fenômenos linguiísticos quanto nas relações interpessoais.

\section{a- auxílio à compreensão}

Nesta categoria, enquadram-se as $\mathrm{R}$ ligadas à facilitação da tarefa do interlocutor na compreensão. Para Marcuschi (1992, p. 129), a distinção entre a $R$ com esta função e as demais torna-se difícil, na medida em que grande parte das $\mathrm{R}$ com função discursiva, voltadas para a atividade dialógica, promovem a compreensão. Para limitar um pouco e tornar a classificação mais enxuta, buscou-se restringir - neste trabalho - essas $R$ somente àquelas que atuam nos reinícios de enunciado, visando esclarecimento. São R que servem como metacomentário e explicitam o dito. São, portanto, segmentos que contêm, geralmente, pequenas expansões ou reformulações parafrásticas com algum acréscimo explicativo ou elucidativo. Segundo Marcuschi, "não é propriamente uma insistência na mesma idéia e sim uma reatualização esclarecedora da mesma idéia" (p. 135)

Novamente é preciso citar o exemplo (8), como um segmento em que esta função é plenamente desempenhada pela R. Logo após L2 repetir a fala de L1 (“desenvolvimento em que sentido?"), com o objetivo de pedir um esclarecimento, L1 se vale da R para modificar sua própria formulação, buscando expandir a noção de desenvolvimento/ desenvolvido: "ato de sair da condição de subdesenvolvido e atingir a condição de desenvolvido".

Nesse exemplo, a sequiência de auto-R com variações sucessivas visa a esclarecer o interlocutor a respeito da pergunta inicial. Este é um caso de multifuncionalidade, podendo-se afirmar que a função secundária é a de expansão. 
ANDRADE, Maria Lúcia da C. V. de Oliveira. A repetição como elemento condutor do tópico discursivo.

b- organização do tópico discursivo

Localizam-se neste nível de relações globais as R que operam na condução do tópico discursivo, visando à sua reintrodução. São R que, de modo geral, estão distanciadas da M. Trata-se da retomada de um tópico discursivo que sofreu um deslocamento de seu centro de relevância por meio de uma digressão lógico-experiencial ou interpessoal.

No exemplo (3), já citado anteriormente, L1 está respondendo a L2 por que resolveu fazer o curso normal, desenvolvendo, então, o tópico "Necessidade de carreira profissionalizante", mas faz uma digressão interpessoal quando se refere ao fato de o relógio estar atrapalhando a continuidade da conversa ("meu relógio está atrapalhando a nossa-...").

Verifica-se, nesse exemplo, que a locutora, por estar preocupada com o horário, substitui a relevância tópica (carreira profissionalizante) por uma relevância não conversacional, tornando-a motivacional, pelo menos para ela que está interessada em terminar a conversação rapidamente. Entretanto, depois de verificar o relógio, L1 continua o tópico que havia interrompido e para isso vale-se da $\mathrm{R}$ do último segmento anterior à digressão: "por uma carreira profissionalizante". Esse novo direcionamento é provocado por necessidades comunicativas que revelam padrões sintáticos diretamente relacionados aos padrões discursivos.

As digressões não se situam numa relação seqüiencial linear de ações, mas num quadro cognitivo em andamento. Contudo, como o texto se produz linearmente, é preciso marcar essa progressão textual e, para isso, o falante lança mão de recursos sintáticos, ou seja, emprega marcas formais que assinalam as condições interacionais, dentre essas marcas tem-se a repetição.

A $\mathrm{R}$ auxilia a reintroduzir o tópico discursivo, pois tem caráter bidirecional (retrospetivo e prospectivo), já que serve para pinçar o tópico que ficou interrompido e, ao trazê-lo novamente à tona, faz com que ele tenha continuidade ou progressão. 
Filologia e Lingüística Portuguesa, n. 2, p. 179-204, 1998.

Vejam-se outros exemplos:

(11) L1 que ela vive acusando é aquela que...

L2 é aquela

L1 toma conta do pessoal ((risos)) oh... agora ah:: - nossa... foi além do que eu... imaginava -...

Doc não::

L1 o horário

Doc pode falar à vonta::de

L $1 \mathrm{ma} /$

Doc nós não temos horário

L1 não por causa das crianças na escola ((risos)) agora a Estela vive dançando... e ela quer ser bailarina... agora

(SP D2 360: 1378-88, p. 171)

L1 está desenvolvendo o tópico "Tendências vocacionais dos filhos”, falando alternadamente de Laura e Estela. A locutora hesita, emprega o marcador agora, hesita novamente e interrompe o que está dizendo porque está preocupada com o horário. Essa relevância motivadora pode ser explicada a partir do contexto situacional, que provoca na locutora a necessidade de informar aos demais que precisa ir embora, pois deve buscar os filhos na escola. A seguir, reintroduz o tópico repetindo o marcador agora, para dar prosseguimento às tendências profissionais das filhas. Na realidade, esse marcador serve como elemento que assinala a mudança de enfoque, ou seja, após falar sobre o horário, volta-se para a vocação da filha (Estela).

(12) Doc gostaríamos que vocês falassem a respeito da cidade e do comércio...

L1 tem saído ultimamente de carro? 
L2 ((risos)) tenho mas você diz sair... fora... sair normalmente para a escola essas coisas?

L1 pegar a cidade ( )

L2 tenho se bem que eu acho que eu conheço pouco a cidade né?... por exemplo se eu for comparar com...

L1 - você viu se está gravando direito aí? -

Doc está está eu já deixo no automático...

L1 - ah o automático não indica velô... -

Doc não... ((vozes distantes))

L2 tenho saído sim...

(SP D2 343:1-13, p. 17)

O documentador começa o inquérito propondo aos interlocutores que desenvolvam o diálogo sobre o tema: a cidade e o comércio. L1 toma o turno e pergunta a L2 se ela tem saído ultimamente de carro, L2 pede um esclarecimento e L1 responde, criando uma digressão retórica didática. L2 passa a responder à questão proposta, mas faz uma pausa e então L1 dirige-se ao documentador, falando a respeito do gravador, produzindo uma digressão interpessoal imediata, pois relaciona-se ao contexto situacional.

Nesse exemplo, a retomada do tópico prévio se dá por meio de uma R. Constata-se que L2 volta ao tópico "Sair de carro" repetindo não a expressão imediatamente anterior à digressão, mas o verbo sair que é o núcleo de sua resposta "tenho saído sim".

(13) L1 ～） correto... e:: se vê a:: própria tendência... de:: de como os advogados estão hoje em dia... eles procuram se especializar... nas coisas que estão mais em moda inclusive desapropriação é uma delas ((ruídos, vozes))... eu:: eu acho que a última prefeitura que nós tivemos em que houve assim a... ((ruídos)) uma 
Filologia e Lingüística Portuguesa, n. 2, p. 179-204, 1998.

GRANde desapropriação ... talvez algum de nós sido até sofrido com isso ((risos)) mas...

você vê:: realmente eles procuraram se especializar nisso... certo? atendendo a um a uma necessidade do momento...

(SP D2 62: 1210-19, p. 89)

Os locutores desenvolvem o tópico "Mercado de trabalho para os advogados". L1 toma o turno, complementando o comentário feito por L2, e introduz uma digressão lógico-experiencial para exemplificar a sua colocação através de "inclusive”. Após o trecho digressivo, L1 reintroduz o tópico anterior, repetindo a oração "eles procuram se especializar", que é introduzida pelo marcador mas... você vê:: realmente.

c- promover a interação

A R opera como confirmação ou endosso quando a M proposta como sugestão por um interlocutor for aprovada e incorporada na fala do outro. Esta função incorporadora caracteriza-se por realizar-se através de uma hetero- $R$ e revela um alto grau de envolvimento entre os interlocutores na atividade interacional.

Um caso típico é o segmento (14). L2 emite uma opinião sobre o comportamento do filho de sua interlocutora e, ao empregar o marcador de assentimento (né?), sugere um pedido de confirmação, que é respondido por L1, criando uma espécie de explicação sobre o que se entende por um menino bem normal: não é um gênio, que apresenta um comportamento quieto, evidenciando que o contexto de conhecimento de mundo é partilhado pelos interlocutores. A volta ao tópico prévio é feita por meio de repetição oracional: "ele passa horas...".

(14) L1 ((...)) então ele gosta muito de desenhar também então ele desenha TOdos os animais pré-históricos com todas as características o nome de cada um... a 
era em que viveu ele gosta... ele gravou muito bem

L2 ahn ahn

L1 ele gosta REalmente ele é vivo... bastante... mas é leVAdo demais sabe?... ele fica duas horas

L2 bem normal um menino bem normal né?

L1 bem normal graças a Deus não é nenhum:: geniozinho assim... quieto...

ele::... passa horas... lendo... mas ele saiu dali toda a energia que ele acumulou ali naquele periodozinho que el/em que ele leu... que:: geralmente não é pequeno esse período... ele sai

ele...

(SP D2 360: 1461-75, p. 173)

Há neste trecho uma exigência conversacional: a fala de L1 consiste, inicialmente, em uma R-próxima (hetero-R) com entonação assertiva do enunciado de L1. O falante utiliza esse recurso para facilitar a produção discursiva de resposta, de modo a poder prosseguir no desenvolvimento do tópico. Entretanto a reintrodução efetiva do tópico prévio somente se dá após uma R-distanciada (auto-R): ele fica duas horas/ ele passa horas, produzida devido à digressão.

Como se pôde verificar pelos exemplos levantados, a $\mathrm{R}$ apresenta características de um planejamento linguíístico local e evidencia-se não só como um mecanismo de composição do texto, mas também como um elemento condutor do tópico discursivo.

Na visão de Koch (1993, p. 16-7), a repetição caracteriza-se por ser "um mecanismo que permeia todas as atividades de composição textual", podendo ocorrer - em formulações fluentes - com finalidade coesiva ou textualizadora, ou ainda como recurso retórico, enfático ou persuasivo, garantindo a coerência textual; pode sinalizar dificuldades de processamento (linearização) e sanar problemas de formulação. Entretanto, quando o locutor faz uso de uma $\mathrm{R}$ após um trecho 
Filologia e Lingüística Portuguesa, n. 2, p. 179-204, 1998.

digressivo, não há problemas de processamento e sim a necessidade de reintroduzir o tópico que ficou suspenso, devido a um deslocamento do foco de relevância em termos de tema e horizonte.

\section{CONCLUSÃO}

Ao observar a ocorrência de R após um trecho digressivo, pôdese verificar que os falantes se valem dessa estratégia para promover, entre outras possibilidades, a condução e manutenção do tópico discursivo, já que ela instaura a solidariedade conversacional entre os parceiros, propiciando envolvimento, dinamismo e continuidade à interação.

Por intermédio da $R$, instaura-se a coesão superficial e as sequiências são encadeadas de modo mais adequado, favorecendo a compreensão. A textualidade se estabelece de modo mais dinâmico, já que permite um envolvimento interpessoal mais estreito. Pode-se dizer, portanto, que a $\mathrm{R}$ contribui para a sintaxe e organização discursiva, na medida em que auxilia na progressão textual no nível linear (coesão), ou seja, nas topicalizações, ênfases ou manutenção dos referentes e no nível hierárquico (coerência), fazendo emergir uma forma de relevância (marginal, motivacional, metaconversacional).

\section{BIBLIOGRAFIA}

ANDRADE, M. L. C. V. O. (1995) Digressão: uma estratégia de condução do jogo textual-interativo. Tese de Doutoramento, Universidade de São Paulo.

BROWN, G. \& YULE, G. (1983) Discourse analysis. Cambridge, Cambridge University Press.

CASTILHO, A. T. de e PRETI, D. (1987) A linguagem falada culta na cidade de São Paulo: Diálogos entre dois informantes. São Paulo, T. A. Queiroz/FAPESP, vol. II.

DASCAL, M. \& KATRIEL,T. (1979) Digression a study in conversational coherence. In PETOFI, J. S. (ed.) Text vs. sentence, Hamburg, Buske, vol. XXIX, p. 76-95. 
ANDRADE, Maria Lúcia da C. V. de Oliveira. A repetição como elemento condutor do tópico discursivo.

GARDNER, R. (1987) The identification and role of topic in spoken interation. Semiotica, 65, p. $129-41$.

HALLIDAY, M. A. K. (1978) Language as social semiotic. The social interpretation of language and meaning. London, Edward Arnold.

(1989) Part A. In HALLIDAY, M. A. K. \& HASAN, R. Language, context, and text: aspects of language in a social-semiotic perspective. Series Editor: Frances Christie. Oxford, Oxford University Press.

HASAN, R. (1989) Part B. In HALLIDAY, M. A. K. \& HASAN, R. Language, context, and text: aspects of language in a social-semiotic perspective. Series Editor: Frances Christie. Oxford, Oxford University Press.

KEENAN, E. O. \& SCHIEFFELIN, B. B. (1976) Topic as a discourse notion: a study of topic in conversation of children and adults. In CHARLES, N. (ed.). Subject and topic. New York, Academic Press, p. 335-84.

KOCH, I. G. V. et alii (1992) Organização tópica da conversação. In ILARI, R. (org.) Gramática do português falado: níveis de análise linguística, vol. II, Campinas, Editora da UNICAMP, p. 357-439.

KOCH, I. G. V. (1993) A repetição como mecanismo estruturador do texto falado. In KOCH, I. G. V. e SCHLIEBENLANGE, B. (orgs.) . Linguistik in Brasilian. Tubingen, Niemeyer (no prelo).

(1994) Funções retóricas e interativas da repetição. Boletim da ABRALIN, 15 de julho de 1994, p. 153-8.

MARCUSCHI, L. A. (1990) A repetição na língua falada e sua correlação com o tópico discursivo. Recife, UFPE, versão preliminar.

(1992) A repetição na língua falada: formas e funções. Tese para o Concurso de Professor Titular. Recife, UFPE.

ABSTRACT: The purpose of this paper is to observe how, after the digression, the use of repetition is a conductor element of the discourse topic. The digression is a kind of topic movement that suspends momentarily the previous discourse topic, bringing a peculiar cadence to the text development . For the study of repetition, to follow the Marcuschi's theoretical proposal (1992) typology is divided in two levels: formal and functional.

Keywords: digression, repetition, discourse topic. 